\title{
Люминесценция приповерхностного гетероперехода GaAs/AlAs В гетероструктурах на основе AlAs
}

\author{
(C) В.Е. Никифоров ${ }^{2}$, Д.С. Абрамкин ${ }^{1,2}$, Т.С. Шамирзаев ${ }^{1,2,3, \text { ฯ }}$ \\ ${ }^{1}$ Институт фризики полупроводников им. А.В. Ржанова \\ Сибирского отделения Российской академии наук, \\ 630090 Новосибирск, Россия \\ ${ }^{2}$ Новосибирский государственный университет, \\ 630090 Новосибирск, Россия \\ ${ }^{3}$ Уральский фредеральный университет, \\ 620002 Екатеринбург, Россия \\ E-mail: tim@isp.nsc.ru
}

(Получена 27 апреля 2017 г. Принята к печати 12 мая 2017 г.)

Высокая реакционная способность алюминия приводит к тому, что поверхность гетероструктур на основе AlAs необходимо защищать от окисления слоем GaAs. B результате в приповерхностной области таких гетероструктур всегда есть гетеропереход GaAs/AlAs. В работе показано, что при нерезонансном оптическом возбуждении структур с этим гетеропереходом связана полоса фотолюминесценции, интенсивность которой определяется толщиной и типом легирования защитного слоя GaAs.

DOI: 10.21883/FTP.2017.11.45112.26

\section{1. Введение}

Широкозонный полупроводник AlAs активно используется при создании оптоэлектроных гетероструктур с квантовыми ямами (КЯ) и квантовыми точками (КТ) для фундаментальных исследований и практического применения [1]. Из-за высокой реакционной способности алюминия, который сильно взаимодействует с содержащимся в атмосфере кислородом, гетероструктуры на основе AlAs защищают тонким слоем GaAs. Поэтому в приповерхностной области гетероструктур на основе AlAs всегда есть гетеропереход GaAs/AlAs. При нерезонансном возбуждении таких гетероструктур излучением с энергией фотонов, превышающей ширину запрещенной зоны AlAs, с этим гетеропереходом может быть связана полоса фотолюминесценции (ФЛ), перекрывающаяся с ФЛ от квантовых ям и точек.

В данной работе мы показываем, что в гетероструктурах InAs/AlAs с квантовыми точками появляется дополнительная полоса ФЛ, связанная с приповерхностным гетеропереходом GaAs/AlAs, а ее интенсивность, определяется толщиной и типом легирования защитного слоя GaAs.

\section{2. Детали эксперимента}

В работе изучались гетероструктуры InAs/AlAs c квантовыми точками, выращенные методом молекулярно-лучевой эпитаксии на полуизолирующих подложках GaAs c ориентацией (001). Структуры содержали один слой КТ между слоями AlAs. Технология выращивания гетероструктр подробно описана в работе [2]. Для защиты верхнего слоя AlAs от окисления выращивался покровный слой GaAs. Были выращены нелегированные гетероструктуры с толщиной покровного слоя 5 и
20 нм. Дополнительно выращивались гетероструктуры с покровным слоем толщиной 20 нм, легированным донорной (кремний) или акцепторной (бериллий) примесью до уровня $2 \cdot 10^{18} \mathrm{~cm}^{-3}$. Последовательность слоев в легированных и нелегированных гетеростуруктурах с толщиной покровного слоя 20 нм приведена на рис. 1.

Спектры люминесценции измерялись на установке, построенной на основе спектрографа Acton Advanced SP2500A, оснащенного охлаждаемой жидким азотом ПЗС-камерой Spec-10 System. Стационарная фотолюминесценция возбуждалась полупроводниковым GaNлазером (энергия фотона $h v=3.06$ эВ). Плотность мощности возбуждения составляла $25 \mathrm{BT} / \mathrm{cm}^{2}$. Измерения проводились при температуре жидкого азота. Время-разрешенная ФЛ возбуждалась $\mathrm{N}_{2}$-лазером $(h v=3.68$ эВ) с частотой следования импульсов 1 кГц,

\begin{tabular}{c}
\hline $20 \mathrm{~nm}\{i, n, p\}$-GaAs \\
\hline $30 \mathrm{~nm}\{i, n, p\}$-AlAs \\
\hline $70 \mathrm{~nm} i$-AlAs \\
\hline QDs InAs \\
\hline $60 \mathrm{~nm} i$-AlAs \\
\hline semi-insulating GaAs $(001)$ \\
\hline
\end{tabular}

Рис. 1. Последовательность слоев в легированных и нелегированных гетеростуруктурах InAs/AlAs с толщиной покровного слоя 20 нм. 
длительностью импульса 7 нс и плотностью энергии в импульсе 1.75 мкДж/см ${ }^{2}$, что соответствует плотности мощности в импульсе $250 \mathrm{BT} / \mathrm{cm}^{2}$ и средней плотности мощности $1.75 \mathrm{MBT} / \mathrm{cm}^{2}$. Время-разрешенная ФЛ измерялась фотоэлектронным умножителем ФЭУ-79 в режиме время-коррелированного счета фотонов.

Травление поверхностного слоя гетероструктур проводилось в растворе $\mathrm{H}_{3} \mathrm{PO}_{4}: \mathrm{H}_{2} \mathrm{O}_{2}: \mathrm{H}_{2} \mathrm{O}$ с соотношением концентраций $3: 2: 50$ [3].

Расчет зонных диаграмм гетероструктур проводился с использованием программного пакета Nextnano ${ }^{++}$, основные приближения, использованные при расчетах диаграмм, приведены в работе [2].

\section{3. Результаты эксперимента}

Спектры ФЛ нелегированных гетероструктур InAs/AlAs c различной толщиной покровного слоя показаны на рис. 2. В спектрах присутствуют две полосы ФЛ: высокоэнергетическая, обозначенная на рисунке как $\mathrm{QD}$, обусловленная рекомбинацией носителей заряда в квантовых точках InAs [2], и низкоэнергетическая, обозначенная на рисунке как S. Отношение интенсивностей этих полос изменяется при изменении толщины покровного слоя GaAs. В гетероструктуре с толщиной покровного слоя 20 нм интенсивность низкоэнергетической полосы S в 1.5 раза больше интенсивности высокоэнергетической полосы QD. При уменьшении толщины покровного слоя до 5 нм интенсивность полосы QD воз-

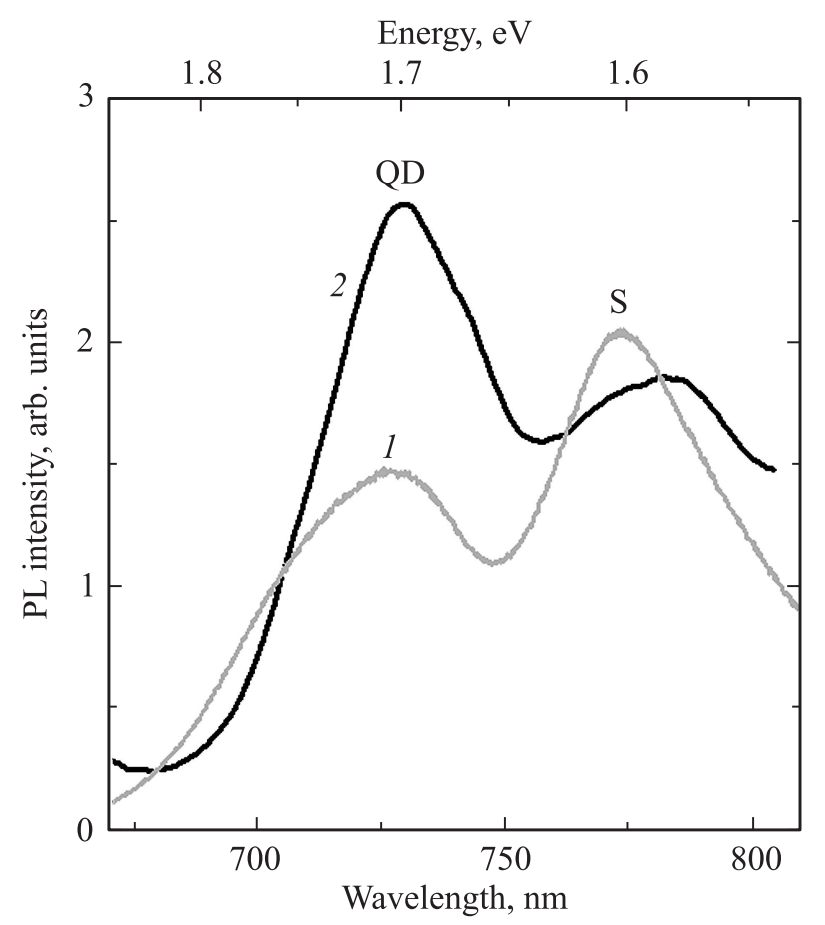

Рис. 2. Спектры низкотемпературной $(77 \mathrm{~K})$ фотолюминесценции (PL) нелегированных гетероструктур InAs/AlAs с толщиной покровного слоя GaAs 20 (1) и 5 нм (2).

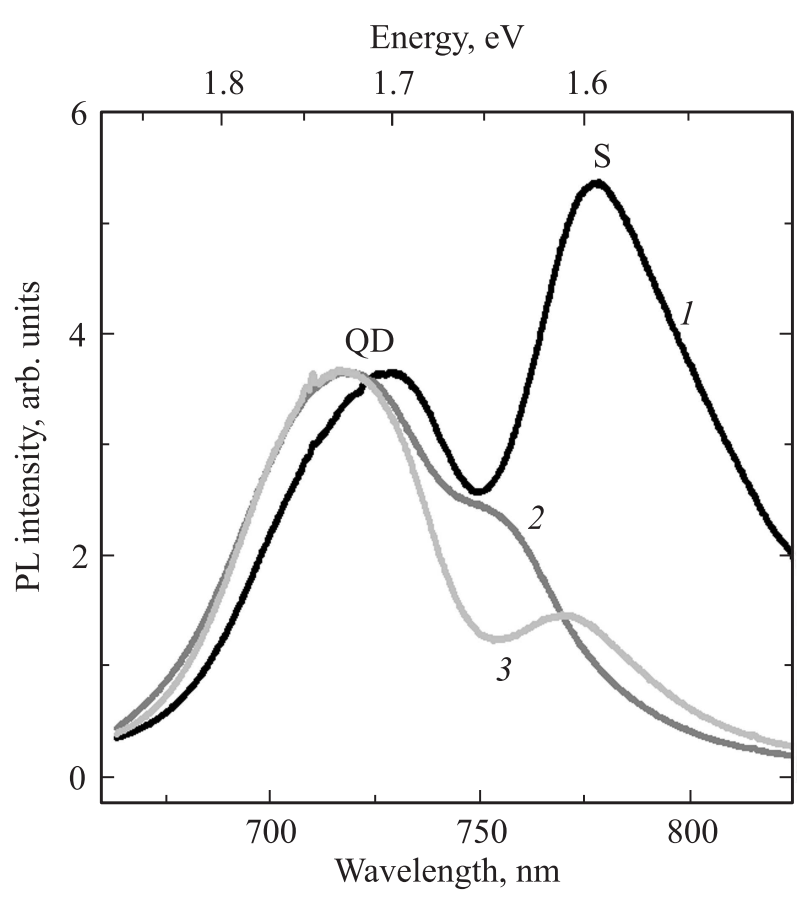

Рис. 3. Спектры низкотемпературной $(77 \mathrm{~K})$ фотолюминесценции (PL) гетероструктур InAs/AlAs с толщиной покровного слоя GaAs 20 нм: нелегированного (1), легированных донорами (2) и акцепторами (3).

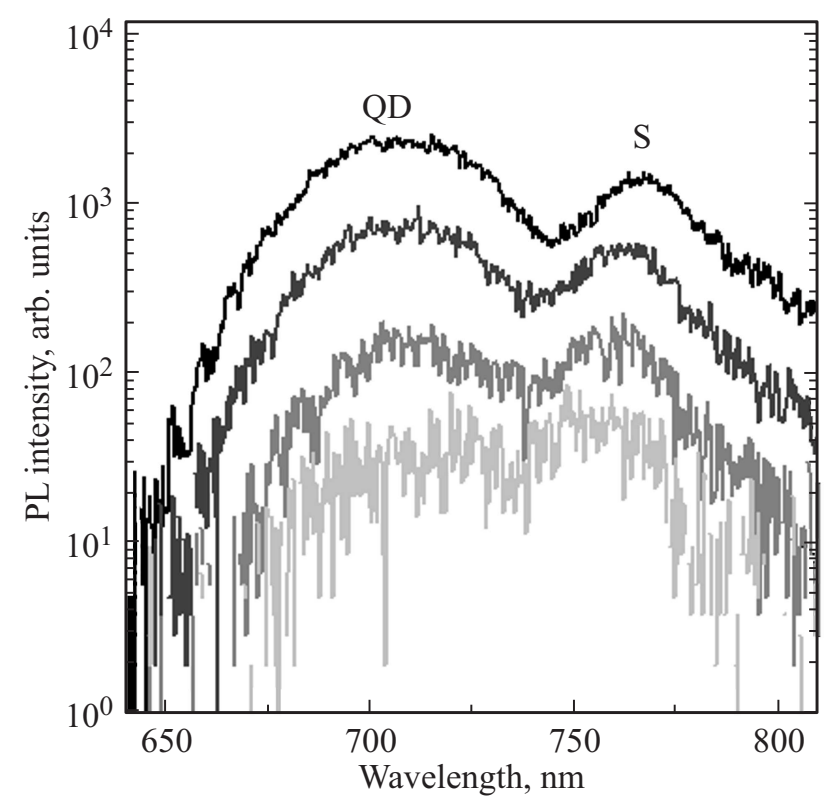

Рис. 4. Время-разрешенные спектры низкотемпературной $(77 \mathrm{~K})$ фотолюминесценции (PL) нелегированной гетероструктуры InAs/AlAs с толщиной покровного слоя GaAs 20 нм, измеренные через (сверху вниз) 0.2, 0.4, 0.8 и 1.6 мкс после импульса возбуждения.

растает, а относительная интенсивность полосы $\mathrm{S}$ уменьшается до значения 0.7 от интенсивности полосы QD.

Спектры ФЛ гетероструктур InAs/AlAs с толщиной покровного слоя 20 нм, легированного донорами и ак- 
цепторами, приведены на рис. 3. Видно, что легирование покровного слоя как донорами, так и акцепторами не приводит к изменению интенсивности полосы QD, однако интенсивность полосы $\mathrm{S}$ при легировании уменьшается примерно на порядок величины.

Время-разрешенные спектры ФЛ нелегированной гетероструктуры InAs/AlAs с толщиной покровного слоя 20 нм приведены на рис. 4. Анализ спектров показывает, что затухание ФЛ обоих полос после возбуждающего импульса неэкспоненциально, причем полоса $\mathrm{S}$ затухает медленнее (ее интенсивность уменьшается в 30 раз за 1.4 мкс), чем полоса QD (уменьшение интенсивности в 70 раз за 1.4 мкс).

\section{4. Обсуждение результатов}

Уменьшение относительной интенсивности полосы $\mathrm{S}$ при уменьшении толщины покровного слоя GaAs позволяет высказать предположение о том, что эта полоса связана с рекомбинацией носителей заряда на гетеропереходе $\mathrm{GaAs} / \mathrm{AlAs}$ в приповерхностной области гетероструктуры. При уменьшении толщины приповерхностного слоя GaAs, который обладает большим коэффициентом поглощения лазерного излучения, происходит пространственное перераспределение фотовозбужденных носителей заряда. Их концентрация уменьшается в приповерхностном слое GaAs, при этом увеличивается доля носителей заряда, рожденных поглощенными в AlAs фотонами и продиффундировавших в область

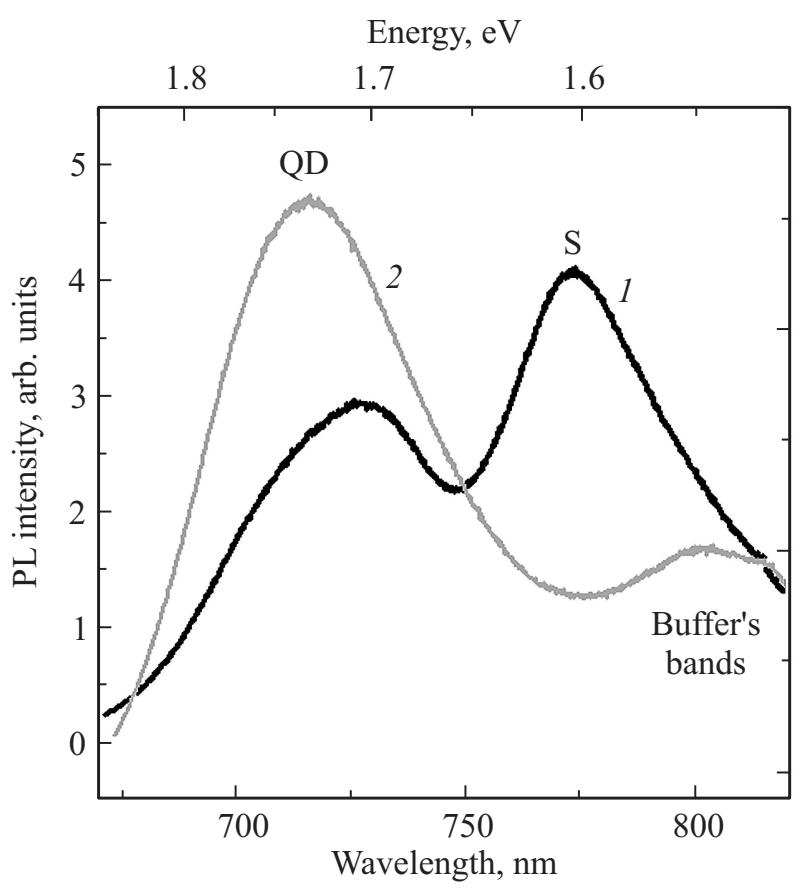

Рис. 5. Спектры низкотемпературной (77 K) фотолюминесценции (PL) гетероструктры InAs/AlAs с толщиной покровного слоя GaAs 20 нм до (1) и после (2) удаления поверхностного слоя GaAs (травления гетероструктуры на глубину 30 нм).
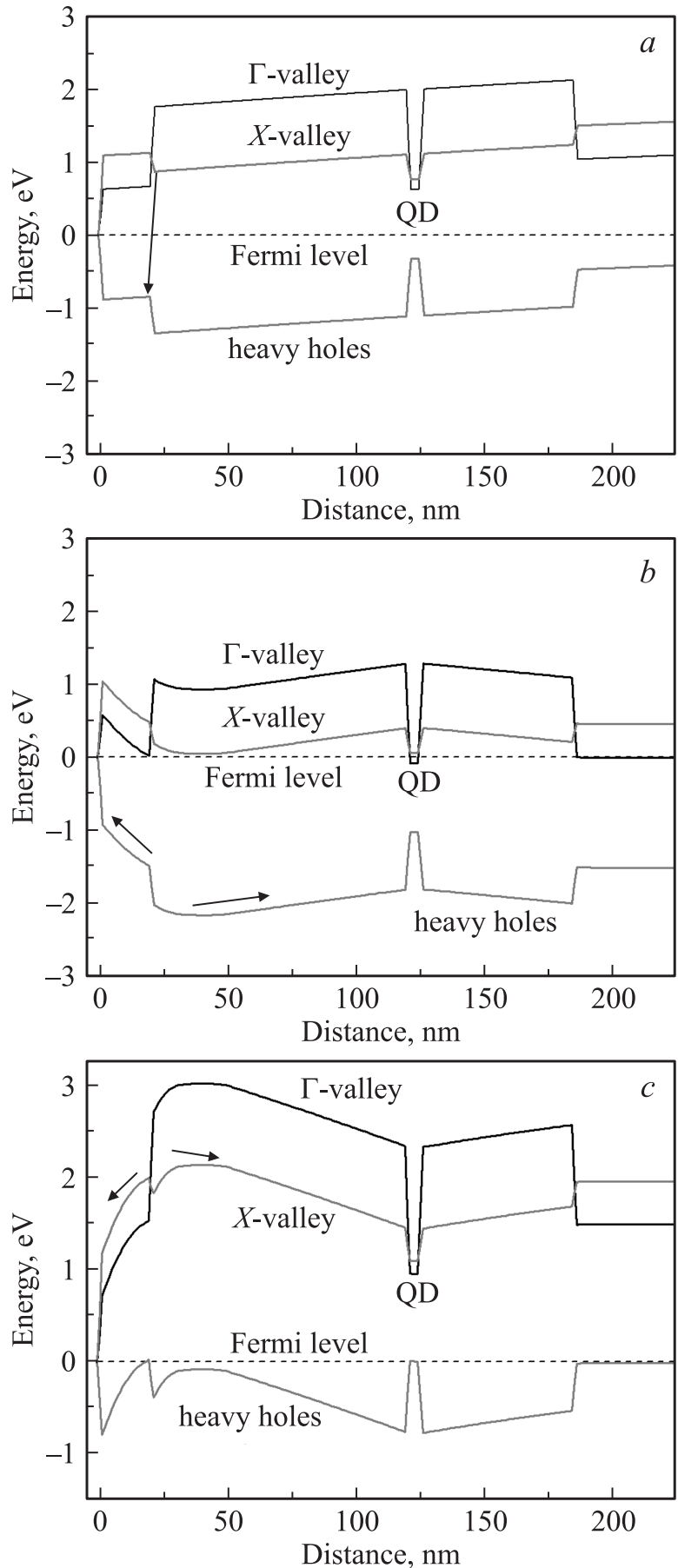

Рис. 6. Зонные диаграммы, рассчитанные для гетероструктур InAs/AlAs с толщиной покровного слоя GaAs 20 нм: $a$ - нелегированная, стрелкой показан оптический переход; $b$ - легированная донорами, $c-$ легированная акцепторами. $b, c$ : стрелками показаны пути делокализации носителей заряда.

локализации КТ. Бо́льшая длительность затухания нестационарной ФЛ в полосе $\mathrm{S}$ по сравнению с затуханием ФЛ в полосе QD подтверждает эту интерпретацию. Действительно, ожидаемая вероятность оптического перехода для разделенных как в реальном пространстве, 
так и в пространстве квазиимпульсов носителей заряда на гетеропереходе GaAs/AlAs с непрямозонным энергетическим спектром второго рода меньше, чем вероятность оптического перехода в непрямозонных КТ InAs/AlAs первого рода, в которых и электрон, и дырка разделены в пространстве квазиимпульсов, но находятся в одной и той же области реального пространства $[3,4]$. Неэкспоненциальнось затухания ФЛ полос QD, S связана с тем, что мы наблюдаем сумму большого количества моноэкспоненциальных кинетик от экситонов, излучающих на одной длине волны, но локализованных в КТ InAs/AlAs различных размера и состава (локализованных на шероховатостях гетероинтерфейса GaAs/AlAs), с разными временами излучательной рекомбинации $[5,6]$.

Для проверки предположения о связи полосы $\mathrm{S}$ с рекомбинацией электронов и дырок на гетерогранице GaAs/AlAs нелегированный поверхностный слой (толщиной $\sim 30$ нм) стравливался. Спектры ФЛ гетероструктур до и после стравливания поверхностного слоя приведены на рис. 5. Видно, что полоса $\mathrm{S}$ после травления, как ожидалось, исчезает, а вследствие пространственного перераспределения фотовозбужденных носителей заряда интенсивность полосы QD возрастает и появляется ФЛ от буферного слоя $\mathrm{GaAs}$, лежащего под нижним слоем AlAs.

Рассмотрим теперь зонные диаграммы изучаемых гетероструктур. Диаграммы, рассчитанные для гетероструктур InAs/AlAs с толщиной покровного слоя 20 нм и различным типом легирования, приведены на рис. 6. Как видно из зонной диаграммы, показанной на рис. 6, $a$. в нелегированной гетероструктуре электроны могут локализоваться в $X$-долине слоя AlAs на гетерогранице, а дырки в приповерхностном слое GaAs. Переход, приводящий к появлению полосы $\mathrm{S}$ в нелегированной гетероструктуре, показан на рис. $6, a$ стрелкой. Легирование приповерхностной области гетероструктуры приводит к модификации ее энергетического спектра. Как это видно из рис. $6, b$ и $c$, легирование донорной (акцепторной) примесью приводит к образованию в приповерхностной области гетероструктуры делокализующего потенциала для дырок (электронов). Отталкивание фотовозбужденных носителей заряда одного знака от гетерограницы $\mathrm{GaAs} / \mathrm{AlAs}$ и является причиной резкого уменьшения интенсивности полосы $\mathrm{S}$ в гетероструктурах с легированным защитным слоем GaAs.

\section{5. Заключение}

В работе изучена фотолюминесценция гетероструктур c KT InAs/AlAs. При нерезонансном оптическом возбуждении в спектрах низкотемпературной фотолюминесценции гетероструктур появляется дополнительная полоса, обусловленная рекомбинацией носителей заряда на приповерхностном гетеропереходе 〈защитный слой $\mathrm{GaAs} /$ /AlAs. Показано, что интенсивность этой полосы уменьшается с уменьшением толщины слоя GaAs изза уменышения в нем концентрации фотовозбужденных носителей заряда и при легировании слоя GaAs изза модификации энергетического спектра гетероперехода GaAs/AlAs, препятствующей локализации фотовозбужденных дырок при легировании приповерхностной области донорами и локализации фотовозбужденных электронов при легировании приповерхностной области акцепторами.

Работа выполнена при финансовой поддержке правительства Российской Федерации, постановление № 211, контракт № 02.A03.21.0006 и РФФИ (проект № 16-02-00242).

\section{Список литературы}

[1] Ж.И. Алфёров. УФН, 172, 1068 (2002).

[2] T.S. Shamirzaev, A.V. Nenashev, A.K. Gutakovskii, A.K. Kalagin, K.S. Zhuravlev, M. Larsson, P.O. Holtz. Phys. Rev. B, 78, 085323 (2008).

[3] Y. Mori, N. Watanabe. J. Electrochem. Soc., 125, 1510 (1978).

[4] T.S. Shamirzaev, J. Debus, D.R. Yakovlev, M.M. Glazov, E.L. Ivchenko, M. Bayer. Phys. Rev. B, 94, 045411 (2016).

[5] T.S. Shamirzaev, J. Debus, D.S. Abramkin, D. Dunker, D.R. Yakovlev, D.V. Dmitriev, A.K. Gutakovskii, L.S. Braginsky, K.S. Zhuravlev, M. Bayer. Phys. Rev. B, 84, 155318 (2011).

[6] I.N. Krivorotov, T. Chang, G.D. Gilliland, L.P. Fu, K.K. Bajaj, D.J. Wolford. Phys. Rev. B, 58, 10687 (1998).

Редактор Л.В. Шаронова

\section{Luminescence of near-surface GaAs/AIAs heterojunction in AIAs-based heterostructures}

\author{
V.E. Nikiforov ${ }^{2}$, D.S. Abramkin ${ }^{1,2}$, T.S. Shamirzaev 1,2,3
}

${ }^{1}$ A.V. Rzhanov Institute of Semiconductor Physics, Siberian Branch of Russian Academy of Science, 630090 Novosibirsk, Russia

${ }^{2}$ Novosibirsk State University, 630090 Novosibirsk, Russia

3 Ural Federal University, 620002 Yekaterinburg, Russia

Abstract A surface of AlAs-based heterostructures must be protected by GaAs cap layer because of high reactivity of aluminum. Thus, the near-surface region of such heterostructures always contains a heterojunction GaAs/AlAs. The photoluminescence band can be associated with the heterojunction at a non-resonant optical excitation. It has been demonstrated that intensity of the photoluminescence band is determined by the doping type and thickness of the GaAs cap layer. 